\title{
Successful Endoscopic Repair of an Iatrogenic Colonic Perforation During Diagnostic Colonoscopy
}

\author{
Seung Hwa Lee, MD, and Yoo Seock Cheong, MD
}

Colonoscopy is the best method for the diagnosis, treatment, and follow-up of colorectal cancer. Although it is generally considered a safe procedure, complications during colonoscopy may occur. The most serious complication is iatrogenic perforation of the colon. Although rare, it can be potentially lethal, especially when it is not recognized and treated immediately. The traditional management of iatrogenic colonic perforation is surgical repair, either by laparotomy or laparoscopy. However, with the recent improvement of endoscopic devices and techniques, endoscopic repair of iatrogenic colonic perforation using endoclips is considered to be both feasible and effective. We successfully used endoscopic clipping to treat a patient with a large perforation of the colon during diagnostic colonoscopy. We believe that the endoscopic repair avoids unnecessary surgery and reduces medical costs. $(\mathrm{J}$ Am Board Fam Med 2012;25:383-389.)

Keywords: Case Report, Colonoscopy, Endoscopic Repair, Gastrointestinal Tract, Iatrogenic Colonic Perforation

Since its first introduction in 1969, colonoscopy has been accepted as the best method for the diagnosis, treatment, and follow-up of colorectal cancer. ${ }^{1} \mathrm{~A}$ recent increasing incidence of colorectal cancer has been observed worldwide. Globally, colorectal cancer is the fourth most common cancer among men and the third most common among women. ${ }^{2}$ Therefore, the demand for colonoscopy is growing rapidly. However, the number of gastroenterologists worldwide is not sufficient to meet the growing demand. Consequently, family physicians have contributed to meeting this demand by performing colonoscopies. ${ }^{3,4}$

Although colonoscopy is almost always safe and has been performed by primary care physicians, ${ }^{5,6}$ complications may occur. Most complications are mild and self-limited, such as abdominal and anal

This article was externally peer reviewed.

Submitted 28 February 2011; revised 22 July 2011; accepted 1 August 2011.

From the Department of Family Medicine, Dankook University College of Medicine, Cheonan, Republic of Korea.

Funding: none.

Conflict of interest: none declared.

Corresponding author: Seung Hwa Lee, MD, Department of Family Medicine, Dankook University College of Medicine, 16-5 Anseo-Dong, Dongnam-Gu, Cheonan-Si, Republic of Korea, 330-715 (E-mail: fmdr@medimail.co.kr). pain, flatulence, and diarrhea. Nevertheless, iatrogenic colonic perforation represents the most serious complication of colonoscopy. The reported overall incidence of perforation ranges from $0.1 \%$ to $0.3 \%$ for diagnostic colonoscopy and from $0.4 \%$ to $1.0 \%$ for therapeutic colonoscopy. ${ }^{7,8}$ The traditional management of iatrogenic perforation is surgical repair by either laparotomy or laparoscopy. With recent, continuous development of endoscopic devices and techniques, endoscopic treatment using endoscopic clipping has been reported, ${ }^{9-11}$ however, perforations larger than $10 \mathrm{~mm}$, which occur during diagnostic colonoscopy, are considered contraindications to endoscopic repair. ${ }^{12}$ We illustrate the management of a patient with a large perforation of the colon during diagnostic colonoscopy, which was treated successfully with endoscopic clipping.

\section{Case Report}

An 83-year-old woman presented with a 2-month history of low abdominal discomfort exacerbated by eating and defecation. There were no associated abdominal symptoms. She had hypertension that was well controlled with medication but had no other medical illness or surgical history. The physical examination was unremarkable. Laboratory 
analysis showed that hemoglobin was decreased to $11.3 \mathrm{~g} / \mathrm{dL}$ (normal range, $12-18 \mathrm{~g} / \mathrm{dL}$ ). The result of additional iron studies were as follows: serum iron, $52.5 \mu \mathrm{g} / \mathrm{dL}$ (normal range, 53-167 $\mu \mathrm{g} / \mathrm{dL}$ ); total iron-binding capacity, $164.3 \mu \mathrm{g} / \mathrm{dL}$ (normal range, $167-513 \mu \mathrm{g} / \mathrm{dL}$ ); ferritin, $59.6 \mathrm{ng} / \mathrm{mL}$ (normal range, $20-60 \mathrm{ng} / \mathrm{mL}$ ). All other laboratory test results were within normal ranges. Chest and abdominal radiographs were normal.

Our patient had never had a previous screening study for gastric or colorectal cancer. Thus, we decided to perform esophagogastroduodenoscopy (EGD) and colonoscopy. The EGD showed chronic atrophic gastritis. After colon preparation with $4 \mathrm{~L}$ polyethylene glycol electrolyte solution, colonoscopy was performed by a family medicine resident. Colonoscopic examination with the regular (adult-sized) colonoscope was performed with the patient under conscious sedation with intravenous $2 \mathrm{mg}$ midazolam. During insertion and withdrawal, the colonoscopy revealed no pathologic findings. Upon retroflexion of the colonoscope at the rectum, however, the patient complained of severe pain. An approximately $15-\mathrm{mm}$ perforation was observed $5 \mathrm{~cm}$ above the anal verge (Figure 1). The resident was replaced immediately by an experienced family physician.

The physician decided to perform endoscopic repair of the perforation because (1) the bowel preparation was excellent, (2) the perforation was detected early, (3) the patient's vital signs were stable, and (4) the patient was cooperative. The $15-\mathrm{mm}$ perforation site of the colon was closed

Figure 1. Colonoscopic view of the perforation site, showing a $15-\mathrm{mm}$ perforation at the distal rectum (5 $\mathrm{cm}$ above the anal verge).

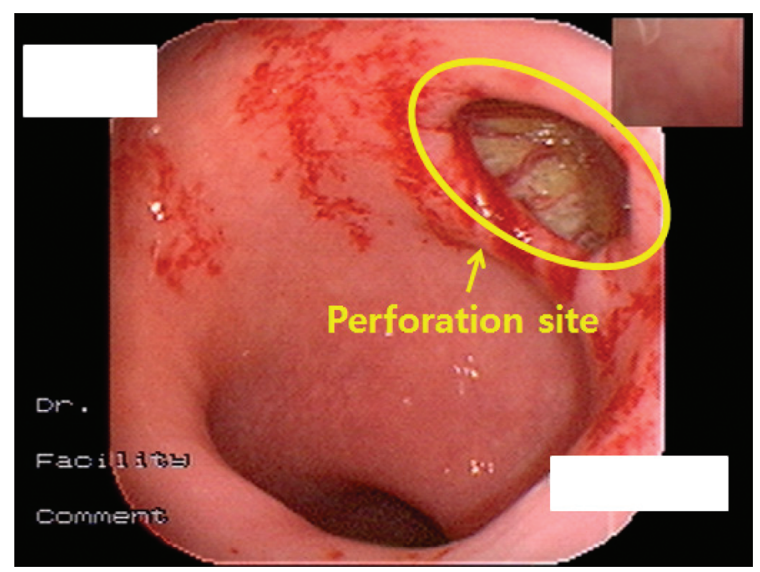

Figure 2. After endoscopic repair with six endoclips, the perforation site was closed. A, B, C: Serial views of endoscopic repair of the iatrogenic colonic perforation.
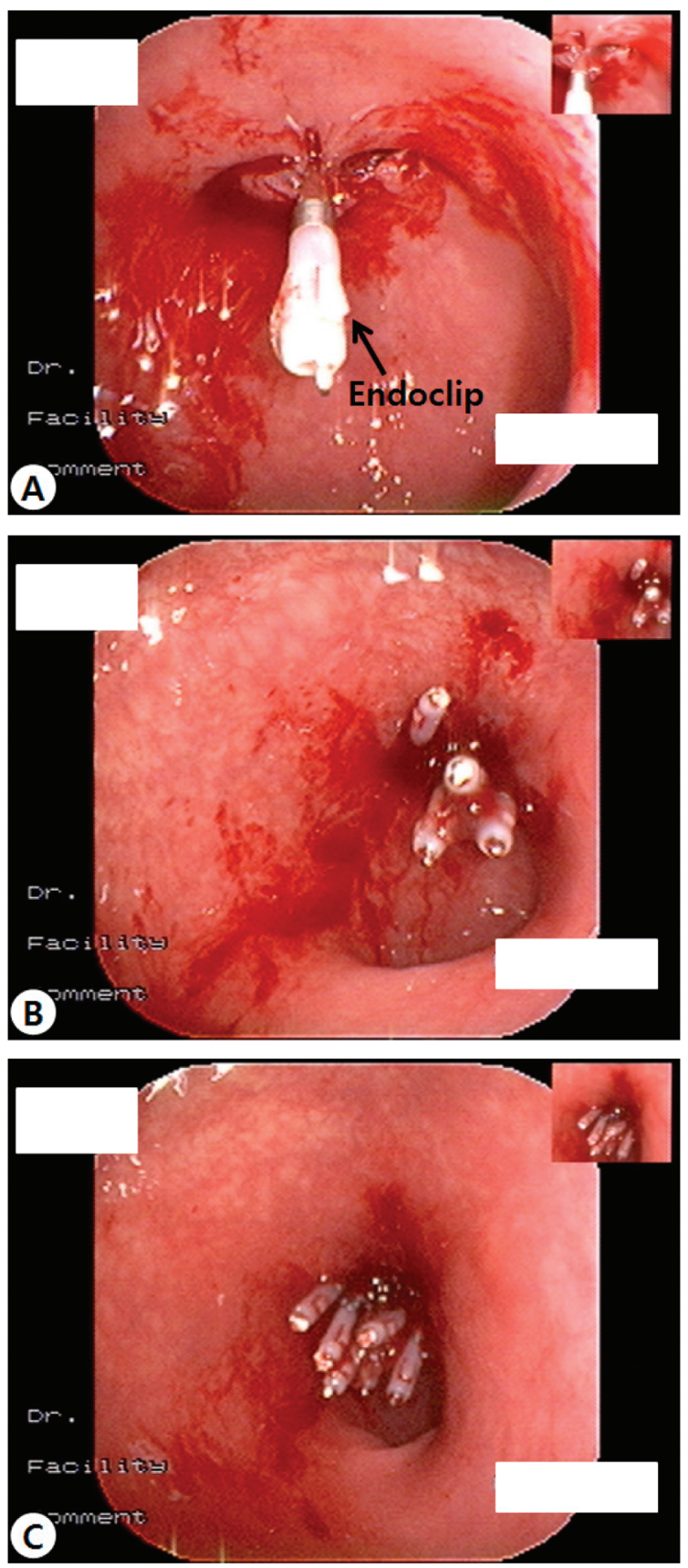

successfully with 6 endoclips (Figure 2A, B, and C); then, the patient was admitted to the hospital for observation. After admission, the patient had nothing by mouth for 3 days; she was maintained on total parenteral nutrition and broad-spectrum intravenous antibiotics. A liquid diet commenced after 4 days because there was no sign of peritonitis 
Figure 3. Colonoscopic finding during follow-up. Two months later, the perforation site was completely healed.

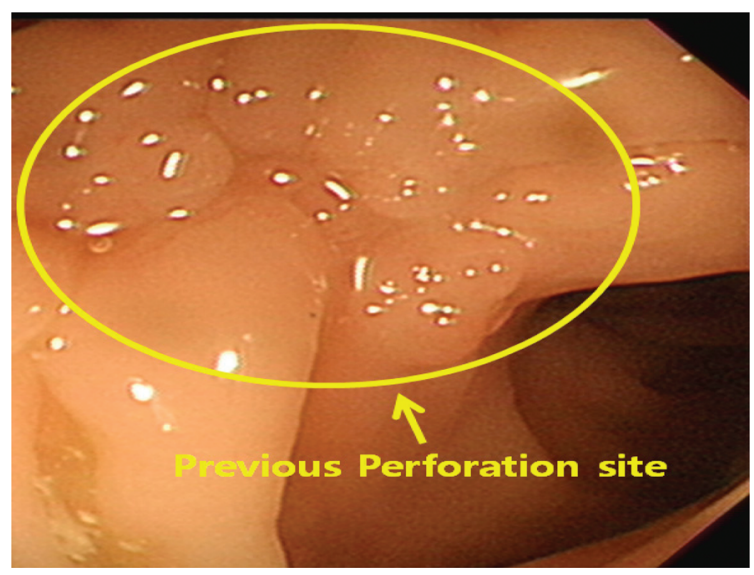

(eg, fever or abdominal tenderness). During the follow-up colonoscopy performed 7 days later, the 6 endoclips used to repair the perforation site were found intact. The patient was discharged after 12 days. During the follow-up colonoscopy performed 2 months later, complete healing of the perforation was found (Figure 3). The patient made an uneventful recovery and remains under our outpatient follow-up observation.

\section{Discussion}

Colorectal cancer is one of the most common malignancies in Western countries and the third lead- ing cause of cancer-related deaths in the United States, with an estimated 142,570 newly diagnosed cases and 51,370 deaths in 2010. ${ }^{13}$ Colorectal cancer seems to be increasing in Asian countries, as well. ${ }^{14,15}$ Colonoscopy allows for greater diagnostic specificity and sensitivity compared with other examinations, such as the stool occult blood test, barium enema, and computed tomography colonoscopy. ${ }^{16}$ In addition, colonoscopy allows for various therapeutic interventions, such as polypectomy, endoscopic mucosal resection, and endoscopic submucosal dissection. Therefore, colonoscopy has become a valuable option for investigating most colonic symptoms and for performing colorectal cancer screening.

The aim of colonoscopy is to see all parts of the colon as clearly as possible. However, there are endoscopic blind spots in the colon (Figure 4). The distal part of the rectum, including the anal canal, is particularly a potential blind spot that needs careful inspection. Thus, retroflexion of the colonoscope in the rectum is required to avoid missing lesions located close to the anal margin and the lower rectum (Figure 5A, B). Retroflexion increases the diagnostic yield of polyps, including precancerous lesions, and reduces the miss rate for the smallest adenomas. ${ }^{17}$ Because it may result in perforation, extreme care should be used when performing rectal retroflexion. Similarly, retroflexion should be stopped in the following circumstances: (1) small or

Figure 4. Schematogram of the colon. Red circles are potential blind spots for colonoscopic visualization.

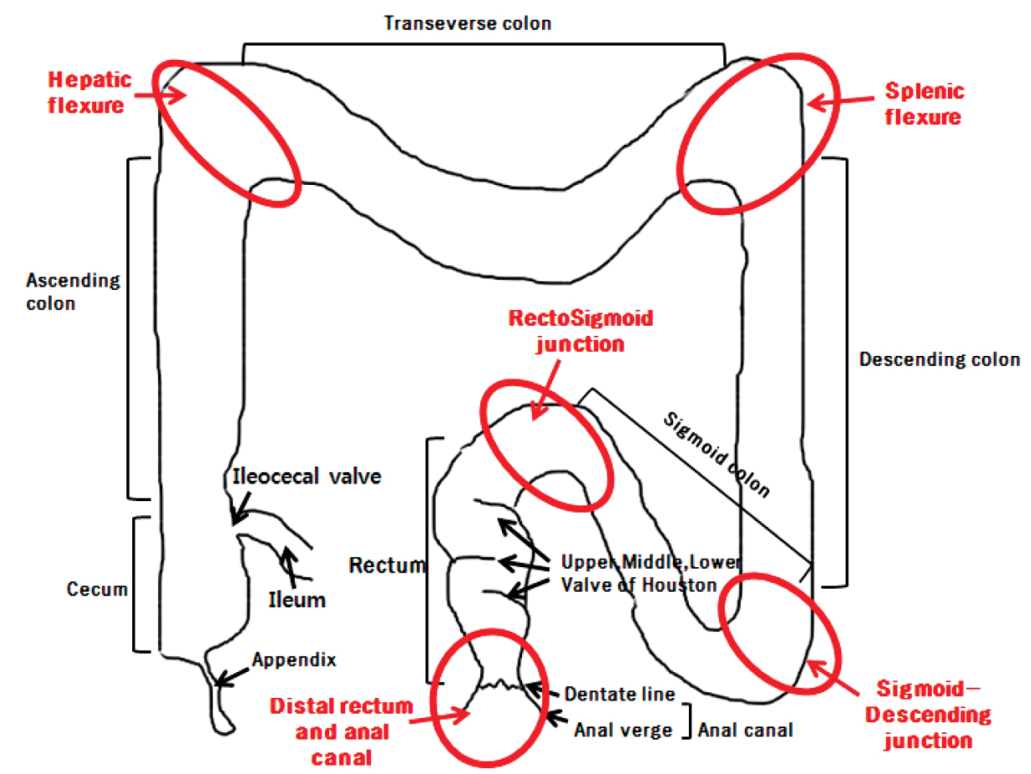


Figure 5. A: Retroflexion view of the distal rectum. B: Typical example in another patient, not the presented case, which showed that retroflexion is valuable for detection of the missed rectal lesion. Left. There was no pathologic lesion in the forward view of the distal rectum. Right. A polyp of the distal rectum was observed in the retroflexion view of the distal rectum.
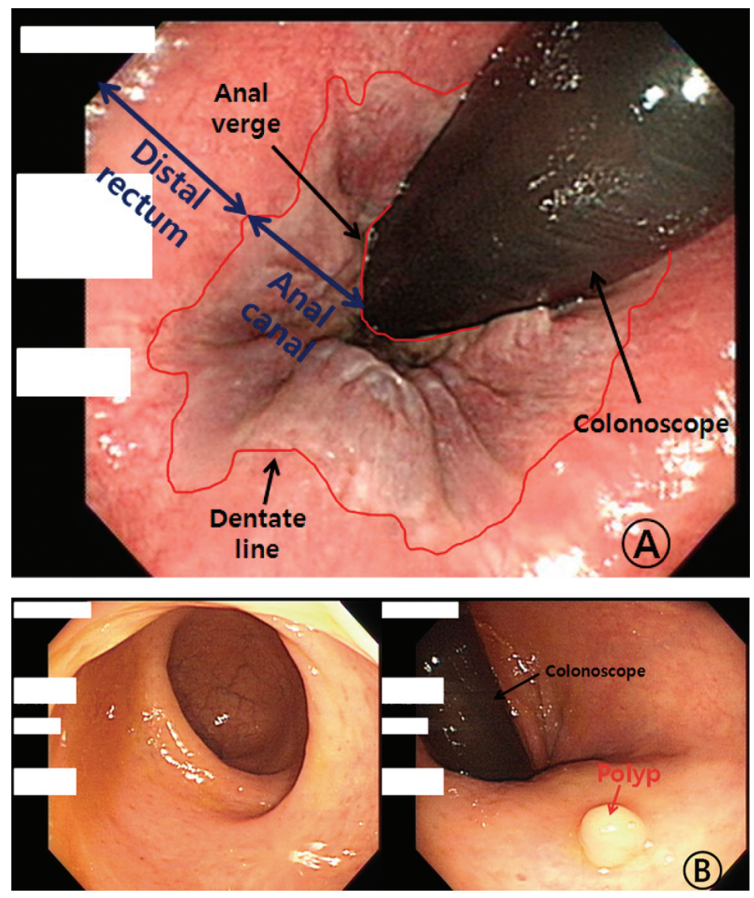

narrowed rectum, (2) signs of resistance to colonoscope progression during this maneuver, and (3) when the patient complaints of pain or discomfort.

Colonic perforation is a rare but severe complication of colonoscopy. It potentially can be lethal, especially when it is not recognized and treated. ${ }^{18}$ There are 3 possible mechanisms leading to perforation $^{19}$ : (1) mechanical perforation, (2) pneumatic perforation, and (3) therapeutic perforation. Mechanical perforation results from excessive pressure of the tip of the colonoscope against the colon wall. Pneumatic perforation occurs because of the overdistension of the colon by excessive air insufflation. Finally, therapeutic perforation is associated with therapeutic interventions. It can be because of the use of the wrong cutting current, causing extensive thermal damage of the colon wall, or to the unskilled handling of either the snare or the endoscopic knife. With regard to the peritoneum, colonic perforation is classified into 2 subgroups $^{20}$ : intraperitoneal perforation and extraperitoneal perforation. Extraperitoneal perforation, as a compli- cation of colonoscopy, is most likely to occur in the lower rectum (usually below the middle valve of Houston), which is retroperitoneal.

It has been demonstrated that the most common site of perforation during diagnostic colonoscopy is the rectosigmoid. ${ }^{21}$ The risk factors for colonic perforation include old age, female sex, colonic diverticulum, history of abdominal surgery, colonic obstruction, and multiple comorbidities. ${ }^{22}$ Therefore, any patient with any of these risk factors should be monitored carefully both during and after colonoscopy, and additional care must be taken when traversing the rectosigmoid area so that the risk of colonic perforation can be minimized and, if it occurs, can be recognized and treated adequately.

In our case, the patient was elderly (83 years old) and a woman. In addition, the perforation site was the distal rectum (ie, below the middle valve of Houston) and the initial examiner lacked experience.

The immediate open laparotomy has long been considered the standard treatment for colonic perforation. ${ }^{23}$ However, this concept has been challenged. Recent advances in both endoscopic devices and techniques have led to the introduction of novel approaches, including endoscopic repair by the use of endoclips. In 1997, Yoshikane et $\mathrm{al}^{9}$ reported the first endoscopic repair of an iatrogenic colonic perforation after endoscopic mucosal resection. After this first report, later reports added strength to the consideration of endoscopic repair of colonic perforation. ${ }^{9,10,24}$ With growing experience and further good results of endoscopic repair of perforations, we can predict that many iatrogenic colonic perforations could be managed without open surgery.

Endoclips have been used successfully in patients with gastrointestinal perforations from various causes. ${ }^{25}$ Endoclips are metal, mechanical accessory devices and are deployed by a delivery device that could be used to insert the endoclip into the lumen via the working channel of the endoscope (Figure 6-A, B, C). Although there have been some concerns about their use, endoclips have been proven to be safe in various clinical conditions and the reported potential complications were minimal. ${ }^{26}$ Endoclips may interfere with radiography or other types of medical imaging, such as computerized tomography and magnetic resonance imaging. ${ }^{27}$ However, spontaneous sloughing of endoclips occurs at approximately 14 to 21 days and clips 
Figure 6. A: The delivery device of the endoclip. B: Left. The endoclip enclosed in plastic sheath. Middle. The endoclip attached to the delivery device Right. Full opening of the endoclip. C: Example of endoscopic repair by using the endoclip.
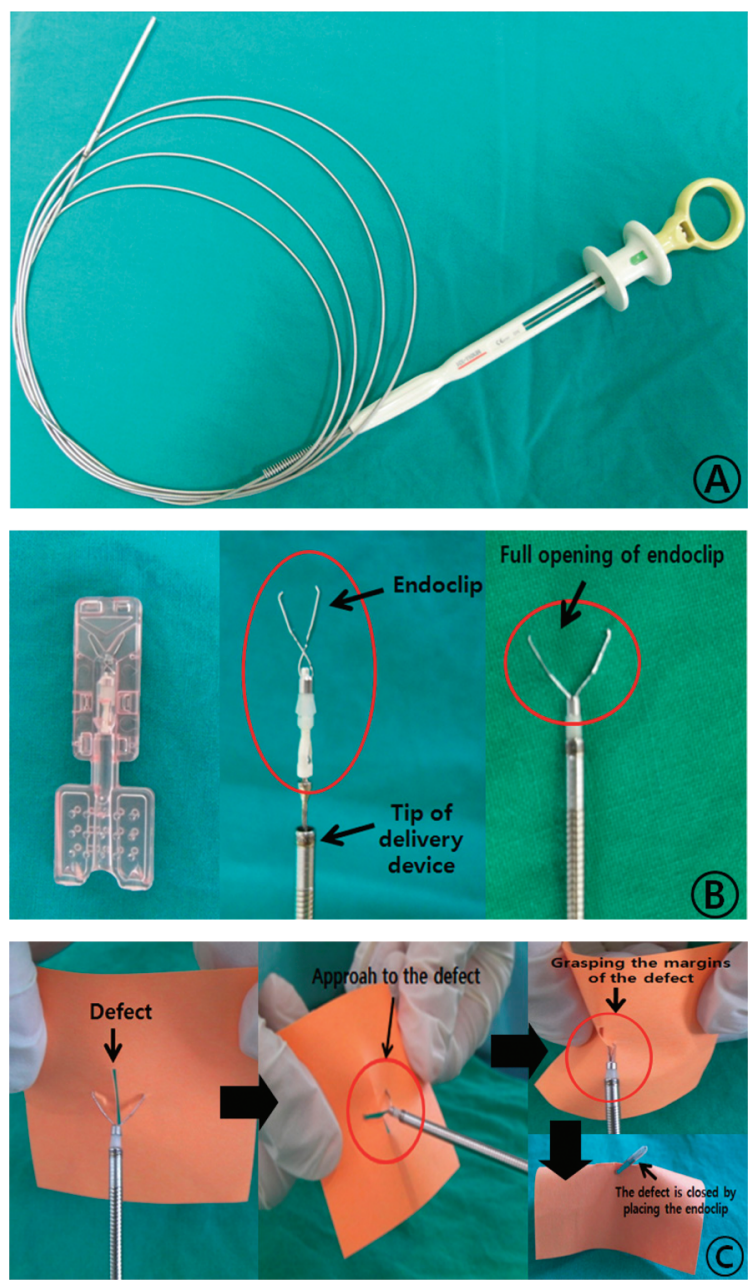

pass uneventfully. ${ }^{28}$ Thus, endoclips do not interfere with further radiologic evaluation in patients undergoing endoscopic repair.

The insertion of a colonoscope into the cecum and the therapeutic intervention associated with colonoscopy, such as polypectomy or endoscopic clipping, is a relatively complex procedure. Thus, considerable training and experience is required for optimal performance of both diagnostic and therapeutic colonoscopy. ${ }^{29}$ Although the minimum number of colonoscopic examinations required to achieve clinical competence has not been well established, at least 50 to 200 colonoscopies have been reported to be required. ${ }^{30-34}$ Nevertheless, because the rate of skill acquisition varies in individual trainees, the competence in colonoscopy should not be evaluated exclusively by the number of colonoscopic procedures performed. Moreover, credentialing for colonoscopy should not be limited to specific medical specialties. ${ }^{35}$ Therefore, future studies in various medical societies of many countries are needed to ascertain the other factors associated with competency, such as cecal intubation rate, adenoma detection rate, complication rate, patient satisfaction, and procedure time. ${ }^{36-38}$

In the current case, the large iatrogenic colonic perforation measuring $15 \mathrm{~mm}$ in length was caused by the examiner during diagnostic colonoscopy. The defect was recognized early and was easily accessible for closure. In addition, the patient's condition was good and the bowel preparation was excellent. These led to the decision to use the endoclips for endoscopic repair of the perforation. Thus, the patient underwent endoscopic repair of the perforation site and avoided surgery. In such a situation, anoscopic repair under direct visualization also would be an option because the perforation site was close to the anal verge. Furthermore, anoscopy sometimes provides more clinically useful information about the lower rectum than can be detected by retroflexion.

\section{Conclusion}

It has been demonstrated that family physicians are able to perform colonoscopy safely. ${ }^{5,6}$ However, during both diagnostic and therapeutic colonoscopy, complications of colonoscopy, such as perforation or bleeding, may occur. The iatrogenic colonic perforation is rare but potentially fatal if not properly diagnosed and treated. Although the traditional management option for the iatrogenic perforation is surgical repair by performing either laparotomy or laparoscopy, these procedures may have significant morbidity. ${ }^{23}$ Recently, endoscopic repair with the use of endoclips has been introduced as an alternative treatment option for iatrogenic colonic perforation. $^{9-11}$

We treated a patient with a perforation of the colon larger than $10 \mathrm{~mm}$, which occurred during diagnostic colonoscopy. In our case, the iatrogenic colonic perforation was treated successfully with endoscopic clipping. The procedure was performed by an experienced family physician and the patient recovered fully without surgery. We believe that endoscopic clipping avoids unnecessary surgery and reduces medical costs. 


\section{References}

1. Wolff WI, Shinya H. Colonofiberoscopy. JAMA 1971;217:1509-12.

2. Jemal A, Center MM, Ward E, Thun MJ. Cancer occurrence. Methods Mol Biol 2009;471:3-29.

3. Wilkins T, LeClair B, Smolkin M, et al. Screening colonoscopies by primary care physicians: a metaanalysis. Ann Fam Med 2009;7:56-62.

4. Newman RJ, Nichols DB, Cummings DM. Outpatient colonoscopy by rural family physicians. Ann Fam Med 2005;3:122-5.

5. Pierzchajlo RP, Ackermann RJ, Vogel RL. Colonoscopy performed by a family physician. A case series of 751 procedures. J Fam Pract 1997;44:473-80.

6. Rodney WM, Dabov G, Cronin C. Evolving colonoscopy skills in a rural family practice: the first 293 cases. Fam Pract Res J 1993;13:43-52.

7. Kavic SM, Basson MD. Complications of endoscopy. Am J Surg 2001;181:319-32.

8. Nelson DB, McQuaid KR, Bond JH, Lieberman DA, Weiss DG, Johnston TK. Procedural success and complications of large-scale screening colonoscopy. Gastrointest Endosc 2002;55:307-14.

9. Yoshikane H, Hidano H, Sakakibara A, et al. Endoscopic repair by clipping of iatrogenic colonic perforation. Gastrointest Endosc 1997;46:464-6.

10. Albuquerque W, Moreira E, Arantes V, Bittencourt P, Queiroz F. Endoscopic repair of a large colonoscopic perforation with clips. Surg Endosc 2008;22: 2072-4.

11. Magdeburg R, Collet P, Post S, Kaehler G. Endoclipping of iatrogenic colonic perforation to avoid surgery. Surg Endosc 2008;22:1500-4.

12. Taku K, Sano Y, Fu K, Saito Y. Iatrogenic perforation at therapeutic colonoscopy: should the endoscopist attempt closure using endoclips or transfer immediately to surgery? Endoscopy 2006;38:428.

13. Jemal A, Siegel R, Xu J, Ward E, et al. Cancer statistics, 2010. CA Cancer J Clin 2010;60:277-300.

14. Muto T, Kotake K, Koyama Y. Colorectal cancer statistics in Japan: data from JSCCR registration, 1974-1993. Int J Clin Oncol 2001;6:171-6.

15. Sung JJ, Lau JY, Goh KL, Leung WK. Increasing incidence of colorectal cancer in Asia: implications for screening. Lancet Oncol 2005;6:871-6.

16. Zauber AG, Lansdorp-Vogelaar I, Knudsen AB, Wilschut J, van Ballegooijen M, Kuntz KM. Evaluating test strategies for colorectal cancer screening: a decision analysis for the US Preventive Services Task Force. Ann Intern Med 2008;149:659-69.

17. Pishvaian AC, Al-Kawas FH. Retroflexion in the colon: a useful and safe technique in the evaluation and resection of sessile polyps during colonoscopy. Am J Gastroenterol 2006;101:1479-83.

18. Waye JD, Kahn O, Auerbach ME. Complications of colonoscopy and flexible sigmoidoscopy. Gastrointest Endosc Clin N Am 1996;6:343-77.
19. Ho HC, Burchell S, Morris P, Yu M. Colon perforation, bilateral pneumothoraces, pneumopericardium, pneumomediastinum, and subcutaneous emphysema complicating endoscopic polypectomy: anatomic and management considerations. Am Surg 1996;62:770-4.

20. Kavin H, Sinicrope F, Esker AH. Management of perforation of the colon at colonoscopy. Am J Gastroenterol 1992;87:161-7.

21. Iqbal CW, Cullinane DC, Schiller HJ, Sawyer MD, Zietlow SP, Farley DR. Surgical management and outcomes of 165 colonoscopic perforations from a single institution. Arch Surg 2008; 143:701-7.

22. Lohsiriwat V, Sujarittanakarn S, Akaraviputh T, Lertakyamanee N, Lohsiriwat D, Kachinthorn U. What are the risk factors of colonoscopic perforation? BMC Gastroenterol 2009;9:71.

23. Hall C, Dorricott NJ, Donovan IA, Neoptolemos JP. Colon perforation during colonoscopy: surgical versus conservative management. Br J Surg 1991;78: 542-4.

24. Barbagallo F, Castello G, Latteri S, et al. Successful endoscopic repair of an unusual colonic perforation following polypectomy using an endoclip device. World J Gastroenterol 2007;13:2889-91.

25. Chuttani R, Barkun A, Carpenter S, et al. Endoscopic clip application devices. Gastrointest Endosc 2006;63:746-50.

26. Grupka MJ, Benson J. Endoscopic clipping. J Dig Dis 2008;9:72-8.

27. Gill KR, Pooley RA, Wallace MB. Magnetic resonance imaging compatibility of endoclips. Gastrointest Endosc 2009;70:532-6.

28. Shin EJ, Ko CW, Magno P, et al. Comparative study of endoscopic clips: duration of attachment at the site of clip application. Gastrointest Endosc 2007;66: $757-61$.

29. Church J, Oakley J, Milsom J, Strong S, Hull T. Colonoscopy training: the need for patience (patients). ANZ J Surg 2002;72:89-91.

30. Wilkins T, Jester D, Kenrick J, Dahl J. The current state of colonoscopy training in family medicine residency programs. Fam Med 2004;36:407-11.

31. Short MW, Kelly KM, Runser LA. Colonoscopy by a family physician: a case series demonstrating health care savings. Mil Med 2007;172:1089-92.

32. Chung JI, Kim N, Um MS, et al. Learning curves for colonoscopy: a prospective evaluation of gastroenterology fellows at a single center. Gut Liver 2010; 4:31-5.

33. Training the gastroenterologist of the future: the Gastroenterology Core Curriculum. Gastroenterology 2003;124:1055-104.

34. Romagnuolo J, Enns R, Ponich T, Springer J, Armstrong D, Barkun AN. Canadian credentialing guidelines for colonoscopy. Can J Gastroenterol 2008;22:17-22. 
35. American Academy of Family Physicians. Colonoscopy (position paper). Available from: http://www.aafp.org/ online/en/home/policy/policies/c/colonoscopyposition paper.html. Accessed 10 Jul 2011.

36. Lee SH, Kwon JE, Cheong YS. Two cases of Trichuris trichiura infection diagnosed by colonoscopy. Korean J Fam Med 2010;31:622-9.
37. Kaminski MF, Regula J, Kraszewska E, et al. Quality indicators for colonoscopy and the risk of interval cancer. N Engl J Med 2010;362:1795-803.

38. Jaboori KA, Domagalski JE, Eckert LD, Short MW. Colonoscopy by a family physician: detecting proximal neoplasia in asymptomatic adults. Mil Med 2011;176:573-7. 